\title{
Severe stenosis occurring in antibiotic sterilised homograft valves ${ }^{1}$
}

\author{
EDWARD J. KOSINSKI, PETER F. COHN, WILLIAM GROSSMAN, ${ }^{2}$ AND \\ LAWRENCE H. COHN
From the Departments of Medicine and Surgery, Peter Bent Brigham Hospital and Harvard Medical School, Boston, Mass., USA

SUMMARY This paper describes 3 patients who developed late severe stenosis in fresh antibiotic sterilised $\vec{\oplus}$ homograft valves. Two were in the aortic position and one in the mitral. All 3 patients underwent o successful reoperation. This complication has not been previously reported in valves prepared by this method.

The introduction of prosthetic heart valves has greatly improved the prognosis of patients with valvular heart disease. However, the prosthetic valve has not been an ideal substitute because of its attendant risk of systemic thromboembolism, haemolysis, and impedance to blood flow (Herr et al., 1968; Hildner and Robinson, 1972; Pine et al., 1976). These disadvantages prompted the introduction of homograft and later heterograft valve replacement, neither of which require anticoagulation while possessing excellent flow characteristics. Initial surgical experience with the homograft was confined to the 'fresh' preparation, but because of logistical difficulty, this method has been largely abandoned. Subsequently, methods were introduced which would allow preservation of the valve until its insertion. These methods consisted of treatment with chemical agents or irradiation and storage in either a frozen or nutrient solution. Extensive experience with both these methods of preservation has shown an unsatisfactory late incidence of valve failure, primarily from cusp rupture, regurgitation, and stenosis (Beach et al., 1972; Gonzalez-Lavin et al., 1972). To preserve the integrity of the 'fresh' homograft, yet adequately sterilise the valve, the technique of antibiotic sterilisation (Yacoub and Kittle, 1970) was introduced and initial long term follow-up evaluation suggests an improvement in valve durability (Angell et al., 1972; Barratt-Boyes et al., 1977). The incidence of aortic cusp rupture

\footnotetext{
'Supported by USPHS Grants.

${ }^{2} \mathrm{Dr}$ Grossman is an Established Investigator of the American Heart Association.
}

Received for publication 3 October 1977 and significant aortic regurgitation is apparently less in the antibiotic treated fresh valve as compared $\overrightarrow{0}$ with valves prepared by chemical or irradiating $\infty$ methods (Barratt-Boyes et al., 1977). The development of significant calcification and subsequent stenosis in antibiotic treated fresh homograft valves in the aortic position has not been previously noted. In the present report, we describe 3 cases of antibiotic sterilised aortic homografts which subsequently developed fibrosis and obstruction to blood flow rather than regurgitation. The correct diagnosis was usually delayed because of unawareness of this late complication.

\section{Clinical material}

CASE 1

A 51-year-old man developed acute rheumatic fever at age 7 , and was asymptomatic until January 1972, when he experienced orthopnoea, paroxysmal nocturnal dyspnoea, and presyncope. Abnormalities of physical examination consisted of a blood pressure of $190 / 60 \mathrm{mmHg}$, a left ventricular heave, and a $N$ murmur of aortic regurgitation. Cardiac catheterisation in February 1972 disclosed moderately severe aortic regurgitation, an ejection fraction of 0.41 , and a regurgitation fraction of $0 \cdot 60$. There was no pressure gradient across the mitral or aortic valves. In $\bullet$ May 1972, the patient underwent aortic valve $\mathbb{D}$ replacement with a free-sewn, unstented $23 \mathrm{~mm}$ : (diameter) antibiotic sterilised fresh homograft valve. No murmur of aortic regurgitation was noted in the first year of follow-up evaluation. He did well until 4 years later, when he noticed progressive $\varnothing$ fatigue and dyspnoea. He was re-admitted to the 
Peter Bent Brigham Hospital (PBBH) in April 1976, and was found to have murmurs of aortic stenosis and aortic regurgitation. Cardiac catheterisation performed via the transseptal route showed a cardiac output of $7.7 \mathrm{l} / \mathrm{min}$ (Fick) with a $50 \mathrm{mmHg}$ gradient across the aortic valve. The aortic valve area was $1.0 \mathrm{~cm}^{2}$. On 12 May 1976 , the homograft valve was removed and a $21 \mathrm{~mm}$ Björk-Shiley valve inserted. Grossly, the cusps were fused at the commissure, and there was poor mobility of the leaflets because of thickening and calcification. Pathological examination of the homograft showed focal degeneration of the valve leaflets, distinct fibrosis with fusion of the valve cusps, and areas of calcification. The patient has done well since his last operation and is asymptomatic 15 months postoperatively.

\section{CASE 2}

A 59-year-old hypertensive man was admitted in August 1972 to hospital because of 3 months of exertional chest pain. Physical examination was consistent with aortic stenosis. He underwent cardiac catheterisation, which revealed a $100 \mathrm{mmHg}$ peak systolic gradient across the aortic valve. The aortic valve area was $0.7 \mathrm{~cm}^{2}$. A heavily calcified stenotic bicuspid aortic valve was replaced with an antibiotic sterilised fresh $24 \mathrm{~mm}$ stented homograft. He did well until 4 years later, when he noticed the onset of fatigue and mild dyspnoea with exertion. He was readmitted to hospital and was found to be in atrial fibrillation. He was cardioverted to normal sinus rhythm, but remained symptomatic and was readmitted in January 1977, at which time cardiac catheterisation using the transseptal approach revealed an $80 \mathrm{~mm}$ peak-to-peak gradient across the aortic valve and a valve area of $0.8 \mathrm{~cm}^{2}$. At operation, the homograft leaflets were calcified and stenotic. A $23 \mathrm{~mm}$ Hancock porcine heterograft bioprosthesis was inserted, his postoperative course was benign, and he has become class 2 in the 9 months since operation.

\section{CASE 3}

A 34-year-old woman had acute rheumatic fever at age 12. She first presented in September 1971 with fatigue and dyspnoea on exertion. There were loud mitral regurgitant and soft mitral stenotic murmurs. Cardiac catheterisation disclosed severe mitral regurgitation. A $29 \mathrm{~mm}$ (diameter) antibiotic sterilised stented aortic valve homograft was inserted in the mitral position in November 1971, and she did well until 5 years later, when she began to notice easy fatiguability. Repeat cardiac catheterisation in March 1977 showed a mean diastolic gradient across the mitral valve of $11 \mathrm{mmHg}$ which when calculated indicated a mitral valve area of $1 \cdot 1 \mathrm{~cm}^{2}$. Mild mitral regurgitation was shown by left ventriculogram. In May 1977, the patient underwent replacement of the stenosed homograft valve. The homograft was noted to have non-mobility of the cusp, and pathological examination showed fibrosis of the cusp leaflets. The homograft was excised and a $33 \mathrm{~mm}$ porcine glutaraldehyde-stabilised heterograft valve was inserted. The patient has done well after the porcine valve replacement and is asymptomatic.

\section{Discussion}

A tissue valve such as the homograft aortic valve offers many advantages over a prosthetic device. Its lack of haemolysis and absence of systemic thromboembolism are factors in its favour. However, the durability of the homograft has been less than optimal. Though the fresh untreated homograft met with early success (Barratt-Boyes et al., 1972), further studies have suggested an unacceptably high rate of valve stenosis and regurgitation (Stinson et al., 1968). In addition, the difficulty of its procurement made it an impractical valve substitute for general usage.

Initial attempts at preserving homograft valves consisted of chemical pretreatment with either betapropiolactone or ethylene oxide and subsequent freeze drying. Long term follow-up studies of chemically prepared valves by Davies et al. (1968), Barratt-Boyes and Roche (1969), Gonzalez-Lavin and Ross (1970), Barratt-Boyes et al. (1972), Gonzalez-Lavin et al. (1972), and Wallace et al. (1974) revealed an incidence of late valve complication of between 13 and 17 per cent. These complications consisted of cusp rupture, avulsion, and calcification with stenosis, which were haemodynamically significant so as to necessitate reoperation or were responsible for the patient's mortality. Smith (1967) reviewed the pathology of the aortic valve homograft and found that all valves with cusp rupture had been freeze dried and, with one exception, had been sterilised with a chemical agent. It is now known that chemical pretreatment and freeze drying fragments the collagen fibres and alters the ground substance of the graft, with subsequent diminution in tensile strength. This high incidence of late valve failure made the chemically freeze dried valve an unsatisfactory substitute for the prosthetic device.

Malm and associates (1967) introduced the use of irradiation and freeze drying as a method to improve valve durability. The irradiation technique resulted in improved tensile strength as compared with the chemically prepared method. Unfortunately, clinical studies (Beach et al., 1972; Pacifico et al., 1972; Karp et al., 1974; Wallace et al., 1974) failed to show improved durability of the irradiated freeze 
dried valve. In the series from Malm's report (1967), 15 of the 39 patients receiving irradiated valves experienced graft failure of which 8 required reoperation. Valvular stenosis was a particularly prominent complication and in 5 patients an aortic valve gradient of between 50 and $100 \mathrm{mmHg}$ was verified at cardiac catheterisation. This high incidence of valve failure resulted in the abandonment of the irradiated valve at their institution.

The third method for preserving aortic homografts consists of brief immersion of a freshly harvested valve in a sterilising antibiotic solution followed by storage in a nutrient solution at low temperatures for a prolonged period (Yacoub and Kittle, 1970), thus preserving viability as well as sterility. Long term follow-up studies (BarrattBoyes et al., 1972, 1977; Angell et al., 1972; Yacoub et al., 1973) of patients receiving antibiotic sterilised valves have shown this method of preparation to be superior to either chemical or irradiation methods. The complications reported have been (1) cusp rupture, the incidence being similar to that of the untreated valve but lower than the chemically sterilised valve (Barratt-Boyes et al., 1977), and (2) the development of aortic regurgitation, which occurred mainly in patients with pre-existing aortic dilatation that resulted in initial malposition of the homograft valve (Barratt-Boyes et al., 1977). Strikingly, the incidence of calcification has been very low and stenosis of the homograft valve in the aortic position has not been reported until now. This is in distinct contrast to both the chemical or irradiated treated valve, both of which have a significant incidence of stenosis.

These 3 case reports describe haemodynamically significant stenosis occurring in antibiotic sterilised valves. The first 2 cases represent acquired stenosis of homografts in the aortic position. The genesis of stenosis in these valves is speculative. Malposition of the homograft has been incriminated as a possible mechanism for subsequent fibrosis. It is suggested that the malaligned valve creates turbulence to left ventricular blood flow resulting in injury to the valve leaflets and subsequent fibrosis. This does not appear to be the cause of dysfunction in our 2 patients, as both had an excellent haemodynamic result without any evidence of valve dysfunction until after the first postoperative year. It can be speculated that the subsequent fibrosis, calcification, and stenosis in cases 1 and 2 are the result of an as yet undefined rejection phenomenon (Buch et al., 1971). The third case represents a stenosed homograft in the mitral position. The use of homografts in the mitral position has previously been noted to be associated with a high incidence of primary valve dysfunction (Stinson et al., 1975).
In conclusion, we have reported 3 cases of antibiotically sterilised aortic valve homografts which were inserted in both the aortic and mitral positions and which subsequently developed fibrosis, calcification, and haemodynamically significant stenosis requiring valve replacement. In 2 patients (cases 2 and 3), the preliminary clinical assessment was inaccurate because of unawareness of this potential long term complication of antibiotic sterilised aortic homografts. One should be aware of the possible development of stenosis when assessing the long term follow-up of recipients of antibiotic sterilised aortic homografts. The valves were replaced with Hancock porcine heterografts in 2 patients, and these appear to have more reliable durability (Cohn et al., 1976a), and a Björk-Shiley aortic valve in 1 patient because of a narrow aortic annulus (Cohn et al., 1976b).

\section{References}

Angell, W. W., Shumway, N. E., and Kosek, J. C. (1972). A five year study of viable aortic homografts. Fournal of Thoracic and Cardiovascular Surgery, 64, 329-339.

Barratt-Boyes, B. G., and Roche, A. H. G. (1969). A review of aortic valve homografts over a six and one-half year period. Annals of Surgery, 170, 483-492.

Barratt-Boyes, B. G., Roche, A., Agnew, T. M., Cole, D., Kerr, A., Monro, J. L., Lowe, J. B., and Brandt, P. W. T. (1972). Homograft valves. Medical fournal of Australia, 2, special suppl., 38-44.

Barratt-Boyes, B. G., Roche, A. H. G., and Whitlock, R. M. L. (1977). Six year review of the results of freehand aortic valve replacement using an antibiotic sterilised homograft valve. Circulation, 55, 353-361.

Beach, P. M., Jr., Bowman, F. O., Jr., Kaiser, G. A., Parodi, E., and Malm, J. R. (1972). Aortic valve replacement with frozen irradiated homografts. Circulation, 45 and 46, Suppl. I, 29-35.

Buch, W. S., Kosek, J. C., and Angell, W. W. (1971). The role of rejection and mechanical trauma on valve graft viability. Fournal of Thoracic and Cardiovascular Surgery, 62, 696-706.

Cohn, L. H., Sanders, J. H., Jr., and Collins, J. J., Jr. (1976a). Actuarial comparison of Hancock porcine and prosthetic disc valves for isolated mitral valve replacement. Circulation, 53 and 54, Suppl. III, 60-63.

Cohn, L. H., Sanders, J. H., Jr., and Collins, J. J., Jr. (1976b). Aortic valve replacement with the Hancock porcine xenograft. Annals of Thoracic Surgery, 22, 221-227.

Davies, H., Missen, G. A. K., Blandford, G., Roberts, C. I., Lessof, M. H., and Ross, D. N. (1968). Homograft replacement of the aortic valve: a clinical and pathological study. American fournal of Cardiology, 22, 195-217.

Gonzalez-Lavin, L., al-Janabi, N., and Ross, D. N. (1972). Long term results after aortic valve replacement with preserved aortic homografts. Annals of Thoracic Surgery, 13, 594-606.

Gonzalez-Lavin, L., and Ross, D. (1970). Homograft aortic valve replacement. Fournal of Thoracic and Cardiovascular Surgery, 60, 1-12.

Herr, R. H., Starr, A., Pierie, W. R., Wood, J. A., and Bigelow, J. L. (1968). Aortic valve replacement: a review of six years' experience with the ball-valve prosthesis. Annals of Thoracic Surgery, 6, 199-218. 
Hildner, F. J., and Robinson, M. J. (1972). Complications of Beall valve prosthesis. American fournal of Cardiology, 30, 922.

Karp, R. B., Kirklin, J. W., Kouchoukos, N. T., and Pacifico, A. D. (1974). Comparison of three devices to replace the aortic valve. Circulation, 49 and 50, Suppl. II, 163-169.

Malm, J. R., Bowman, F. O., Harris, P. D., and Kovalik, A. T. W. (1967). An evaluation of aortic valve homografts sterilized by electron beam energy. Fournal of Thoracic and Cardiovascular Surgery, 54, 471-477.

Pacifico, A. D., Karp, R. B., and Kirklin, J. W. (1972). Homografts for replacement of the aortic valve. Circulation, 45 and 46, Suppl. I, 36-43.

Pine, M., Hahn, G., Paton, B., Pappas, G., Davies, D. H., Steele, P., Pryor, R., and Blount, S. G., Jr. (1976). Homograft and prosthetic aortic valve replacement: a comparative study. Circulation, 53 and 54, Suppl. III, 84-89.

Smith, J. C. (1967). The pathology of human aortic valve homografts. Thorax, 22, 114-138.

Stinson, E. B., Angell, W. W., Iben, A. B., and Shumway,
N. E. (1968). Aortic valve replacement with the fresh valve homograft. American fournal of Surgery, 116, 204-209.

Stinson, E. B., Griepp, R. B., Bieber, C. P., and Shumway, N. E. (1975). Aortic valve allografts for mitral valve replacement. Surgery, 77, 861-867.

Wallace, R. B., Londe, S. P., and Titus, J. L. (1974). Aortic valve replacement with preserved aortic valve homografts. fournal of Thoracic and Cardiovascular Surgery, 67, 44-52.

Yacoub, M., and Kittle, C. F. (1970). Sterilization of valve homografts by antibiotic solutions. Circulation, 41 and 42 , Suppl. II, 29-32.

Yacoub, M., Knight, E., and Towers, M. (1973). Aortic valve replacement using fresh unstented homografts. Thoraxchirugie, 21, 451-457.

Requests for reprints to Dr Peter F. Cohn, Cardiovascular Division, Peter Bent Brigham Hospital, 721 Huntington Avenue, Boston, Massachusetts 02115, USA. 